Article

\title{
Chia (Salvia hispanica L.) Flour and Oil Ameliorate Metabolic Disorders in the Liver of Rats Fed a High-Fat and High Fructose Diet
}

Luiza de Paula Dias Moreira ${ }^{1}{ }^{D}$, Bárbara Nery Enes ${ }^{1}$, Vinícius Parzanini Brilhante de São José ${ }^{1}$, Renata Celi Lopes Toledo ${ }^{1}$, Luiz Carlos Maia Ladeira ${ }^{2} \mathbb{D}$, Rodrigo Rezende Cardoso ${ }^{3}$, Vinícius da Silva Duarte ${ }^{4}$, Helen Hermana Miranda Hermsdorff ${ }^{1}$ (D), Frederico Augusto Ribeiro de Barros ${ }^{3}$ (D) and Hércia Stampini Duarte Martino ${ }^{1, *(\mathbb{D}}$

check for updates

Citation: de Paula Dias Moreira, L. Enes, B.N.; de São José, V.P.B.; Toledo, R.C.L.; Ladeira, L.C.M.; Cardoso, R.R.; da Silva Duarte, V.; Hermsdorff, H.H.M.

de Barros, F.A.R.; Martino, H.S.D. Chia (Salvia hispanica L.) Flour and Oil Ameliorate Metabolic Disorders in the Liver of Rats Fed a High-Fat and High Fructose Diet. Foods 2022, 11, 285. https://doi.org/10.3390/ foods11030285

Academic Editor: Domenico Iacopetta

Received: 17 December 2021 Accepted: 17 January 2022

Published: 21 January 2022

Publisher's Note: MDPI stays neutral with regard to jurisdictional claims in published maps and institutional affiliations.

Copyright: (c) 2022 by the authors. Licensee MDPI, Basel, Switzerland. This article is an open access article distributed under the terms and conditions of the Creative Commons Attribution (CC BY) license (https:// creativecommons.org/licenses/by/ $4.0 /)$.
1 Department of Nutrition and Health, Universidade Federal de Viçosa, Viçosa 36570-900, Brazil; luizamdp20@gmail.com (L.d.P.D.M.); barbara.nery.enes@gmail.com (B.N.E.); v_brilhante@hotmail.com (V.P.B.d.S.J.); renatacelly@yahoo.com.br (R.C.L.T.); helenhermana@ufv.br (H.H.M.H.)

2 Department of General Biology, Universidade Federal de Viçosa, Viçosa 36570-900, Brazil; luizmaialadeira@gmail.com

3 Department of Food Technology, Universidade Federal de Viçosa, Viçosa 36570-900, Brazil; rodrigo17cd@yahoo.com.br (R.R.C.); fredbarros@ufv.br (F.A.R.d.B.)

4 Faculty of Chemistry, Biotechnology, and Food Science, The Norwegian University of Live Sciences, 1432 Ås, Norway; vinicius.da.silva.duarte@nmbu.no

* Correspondence: hercia72@gmail.com

\begin{abstract}
We hypothesized that the consumption of chia (Salvia hispanica L.) flour (CF) and chia oil (CO) improves metabolic disorders in the liver of Wistar rats (Rattus norvegicus domestica) fed a high-fat and high-fructose (HFHF) diet. The animals were fed a HFHF diet $(n=30)$ or AIN93-M standard diet $(n=10)$ for eight weeks. After this period, the animals fed HFHF were divided into three groups $(n=10)$ : HFHF diet, HFHF plus $14.7 \%$ of $C F$, and HFHF plus $4 \%$ of CO. Histological and biochemical analyses, gene expression, protein levels related to inflammation, and oxidative stress were evaluated in the liver. The HFHF diet caused lipogenesis, liver steatosis, oxidative stress, and inflammation in the animals. The CF and CO intake increased the liver total antioxidant capacity and superoxide dismutase, decreased nitric oxide levels and liver steatosis. Furthermore, the CF and CO led to the upregulation of Cpt1a and Adipor2, respectively, whereas CF downregulated Srebf1. $\mathrm{CO}$ intake decreased blood glucose, triglycerides, and the animals' body weight. Chia did not show effects on mitigating liver pro-inflammatory status, which it may indicate occurs later. The addition of chia into an unbalanced diet is a good and relevant strategy to reduce liver metabolic disorders caused by the high consumption of fructose and saturated fat.
\end{abstract}

Keywords: oxidative stress; lipogenesis; liver steatosis; inflammation

\section{Introduction}

High consumption of fructose and saturated fat is related to an increase of noncommunicable chronic diseases, such as obesity, insulin resistance, metabolic syndrome, type 2 diabetes, and mainly, nonalcoholic fatty liver disease (NAFLD). Several organs are affected, although it has been mostly related to metabolic dysregulation and livercentered conditions. Liver injury can advance to a specific histological phenotype such as hepatocyte ballooning, macrovesicular steatosis, lobular inflammation, fibrosis, cirrhosis, and hepatocellular carcinoma, which makes it a worldwide public health problem [1-3].

Liver dysregulations may cause insulin resistance, oxidative stress, inflammation, and enhance lipogenesis and beta-oxidation. The synthesis of fatty acids by the excess of glucose and mainly fructose is called de novo lipogenesis, which leads to depletion of 
adenosine triphosphate in the liver. It contributes to cellular stress and increases the risk of developing liver-related complications [4]. Primarily, high intakes of carbohydrates and fatty acids cause saturation of the oxidative pathway. In addition, the increase of adipose tissue is regulated by insulin, which leads to lipolysis of triglycerides (TG), increasing free fatty acids influx, synthesis and retention of lipid in hepatocytes, and the formation of lipotoxic compounds. Besides, these mechanisms can alter the enzymatic antioxidant system and increase lipid peroxidation causing a redox imbalance.

Lipogenesis rates are mainly up-regulated by sterol regulatory element binding transcription factor 1 (SREBP1c)) (synonym Srebf1) and acetyl-CoA carboxylase 1 (Acc1) associated with down-regulation of genes involving fatty acid oxidation like carnitine palmitoyltransferase 1a (Cpt1a), adiponectin receptor 2 (Adipor2), and proliferator-activated receptor alpha (PPAR- $\alpha)[1,5,6]$. Moreover, a systemic and tissue proinflammatory state is also observed in the NAFLD by the activation of the Toll-like Receptor 4 (TLR4)/Nuclear Factor Kappa B (NF-кB) signaling pathways and increased levels of pro-inflammatory cytokines [7]. These metabolic disorders contribute to hyperglycemia and consequent insulin resistance. Furthermore, high levels of hepatic enzymes, such as alanine aminotransferase (ALT) and aspartate aminotransferase (AST), and high levels of uric acid in the liver can indicate liver damage $[8,9]$.

In this sense, the consumption of functional foods and/or their isolated bioactive compounds can reduce the risk of developing metabolic liver disorders and assist in the treatment of NAFLD (Li et al., 2021). From this perspective, the chia seed (Salvia hispanica L.) stands out for its high functional potential exemplified by its dietary fiber, lipids, mainly $\alpha$-linolenic fatty acid (ALA), proteins, vitamins, minerals, and bioactive compounds $[10,11]$. Studies conducted in in vitro models, with animals, and a few clinical trials have demonstrated the benefits of chia [12-14]. A systematic review carried out by our research group [15] demonstrated that the inclusion of chia (whole seed, flour, or oil) into unbalanced diets can reduce several metabolic disorders. Chia oil $(4 \% v / v)$ was also able to reduce body adiposity and insulin resistance in rats fed an HFHF diet [16]. However, the effects of chia on metabolic liver disorders, mainly lipogenesis, oxidative stress, and inflammation in rats fed a HFHF diet remain unclear. Therefore, we hypothesized that the consumption of chia (Salvia hispanica L.) flour (CF) and chia oil (CO) improve lipogenesis, fatty acid oxidation, liver steatosis, oxidative stress, and inflammation in the liver of rats fed a high-fat and high-fructose (HFHF) diet. The aim of this study was to evaluate the effects of $\mathrm{CF}$ and $\mathrm{CO}$ on oxidative stress, liver steatosis, gene expression related to lipogenesis and fatty acid oxidation, and inflammation in the liver of rats fed HFHF.

\section{Materials and Methods}

\subsection{Chia Characterization}

\subsubsection{Raw Material}

The chia seeds used in this study were cultivated in the state of Rio Grande do Sul, Brazil. The seeds were stored at $-20^{\circ} \mathrm{C}$ until further analysis. The seeds were milled every 15 days in a blender (Mondial ${ }^{\circledR}$-model NL-26, Conceição do Jacuípe, (Bahia), Brazil) at level 2 , for $3 \mathrm{~min}$, and stored in vacuum packaging at $-20^{\circ} \mathrm{C}$.

\subsubsection{Chia Oil Extraction}

The chia oil was obtained weekly through the cold pressing of chia flour by using a hydraulic mechanical press (Carver Laboratory Press, Model C 22400-36, Summit, NJ, USA). The oil was collected, filtered, centrifuged at $1050 \times g$, for $15 \mathrm{~min}$ at $7^{\circ} \mathrm{C}$, and stored in amber glass at $-20^{\circ} \mathrm{C}$.

\subsubsection{Chia Proximate Composition}

Chia proximate composition (moisture, ash, proteins, total lipids, dietary fiber, and carbohydrates) was determined by the methods recommended by the Association of Official Agricultural Chemists (AOAC) [17]. 


\subsubsection{Determination of Total Antioxidant Capacity and Total Phenolic of Chia Flour}

The extracts were prepared by adding $2 \mathrm{~g}$ of chia flour into $20 \mathrm{~mL}$ of acetone solution $(70 \%$ acetone/water $)$. The supernatant was shaken $\left(2 \mathrm{~h}, 25^{\circ} \mathrm{C}\right)$, centrifuged $(2865 \times g$, 15 min (Hermle ${ }^{\circledR}$, model Z216MK, Wehingen, Germany), transferred to a beaker and with volume made up to $20 \mathrm{~mL}$ with acetone (70\% acetone/water). Determination of the free radical scavenging capacity of 2,2-diphenyl-1-picrilhydrazil (DPPH) was performed and the anti-radical activity was expressed in $\mu \mathrm{mol}$ equivalent to Trolox/g of the sample ( $\mu \mathrm{mol}$ Trolox/g) [18]. The total phenolic content of the chia flour was determined according to the Folin-Ciocalteu method [19]. The absorbance was read at $765 \mathrm{~nm}$ on a spectrophotometer (Thermo Scientific, Evolution 606, Madison, WI, USA). A standard curve ranging from 0 to 300 ppm of gallic acid (GA), and the results were expressed in $\mathrm{mg}$ of gallic acid equivalents $/ \mathrm{mL}$ of extract of chia flour ( $\mathrm{mg} \mathrm{GAE} / \mathrm{mL})$.

\subsubsection{Peroxide and Acidity Content, and Fatty Acid Profile of Chia Oil}

The chia oil peroxide value was performed according to the procedures recommended by American Oil Chemists Society [20]. The result was expressed as milliequivalents (mEq) of peroxide/1000 $\mathrm{g}$ of oil sample. Acidity was determined and the results were expressed per $\mathrm{mg}$ of $\mathrm{KOH} / \mathrm{g}$ of oil [21]. The fatty acids composition of fatty acids of chia oil was determined by gas chromatography, adapted for vegetable oil [22]. Then, $100 \mu \mathrm{L}$ of the chia oil was added to $4 \mathrm{~mL}$ of $0.5 \mathrm{M} \mathrm{KOH}$ in methanol for basic catalysis for $30 \mathrm{~min}$, vortexed each $5 \mathrm{~min}$. After the reaction, $2 \mathrm{~mL}$ of distilled water was added. Following this, $5 \mathrm{~mL}$ of hexane (Honeywell-Riedel-de Haen) was added for the extraction of fatty acid methyl esters. The samples were centrifuged (Quimis Centrifuge) at $1050 \times g$ for $2 \mathrm{~min}$, and the organic phase was collected. After, $0.3 \mathrm{~g}$ of anhydrous sodium sulfate was added to the organic phase to absorb the remaining water. The material was filtered (Teflon membrane (PTFE), $22 \mu \mathrm{m}$ ) and poured into a vial tube. The methyl esters were analyzed in a gas chromatograph (Shimadzu GC-2010) with an automatic injector, using a flame ionization detection system (FID), using a capillary column of fused silica SP-2560, with an $0.18 \mathrm{~mm}$ internal column diameter and the $75 \mathrm{~m}$ length. The identification of fatty acids was compared through the retention time of fatty acids in the samples F.A.M.E. Mix C14-C22-Sigma-Aldric, St. Louis, MO, USA), using hexane as a solvent.

\subsection{Animals and Experimental Design}

\subsubsection{Animals}

The study was carried out with forty male Wistar rats (Rattus norvegicus domestica), 45-50 days old. The study protocol was approved by the Ethics Commission on Animal Use (CEUA) at the Federal University of Viçosa (CEUA/UFV-protocol no. 89/2018; date of approval: 21 February 2019) and followed the university guidelines for animal use for Animal Biomedical Research. The rats were obtained from the Central Animal Facility of the Center for Biological Sciences and Health at the Federal University of Viçosa, Minas Gerais, Brazil. The animals were kept in individual stainless-steel cages, under controlled conditions $\left(22^{\circ} \mathrm{C} \pm 2{ }^{\circ} \mathrm{C}, 12: 12\right.$-h light-dark cycle $)$.

\subsubsection{Experimental Design and Diets}

The experimental period was divided into two phases (Figure 1). In the first one (eight weeks), the rats were randomized by body weight (b.w.) into two groups and received a modified standard diet AIN93-M (AIN93-M group) [16], b.w. = $156.0 \pm 17.0$ g, $n=10$; or high-fat and high-fructose diet (HFHF group; b.w. = $156.5 \pm 17.9 \mathrm{~g}, n=30$ ) for eight weeks. The HFHF diet contained $4 \%(w / w)$ of soybean oil, $31 \%(w / w)$ of lard, and $20 \%(w / w)$ of fructose [16]. After this period, the animals fed the HFHF diet were randomized according to body weight into three different groups $(n=10)$ : control: HFHF (b.w. = $366.8 \pm 35 \mathrm{~g}$ ); chia oil (CO): HFHF diet plus chia oil (CO) (b.w. = $362.5 \pm 34.8 \mathrm{~g}$ ); or chia flour (CF) (b.w. $=362.4 \pm 35.4 \mathrm{~g})$ : HFHF plus CF $14.7 \%$ of chia flour, for ten weeks. The vitamins and minerals mix of the diets were administrated equally for all diets, as well as 
the quantity of macronutrients, following the recommendation of a standard diet AIN93-M, with modifications: the replacement of protein source casein for albumin. To calculate the chia treatment diets, soybean oil (4\%) was replaced by chia oil (4\%) (CO diet); or 4\% lipid from chia flour, which is equivalent to $14.7 \%$ of chia flour (CF diet). To calculate the CF diet, chia flour chemical composition was considered (Figure $2 \mathrm{~A}$ ). Since $14.7 \%$ of chia flour contains $5.58 \%$ of dietary fiber, the other diets (AIN93-M, HFHF, and CO) contained the same amount of microcristalline cellulose (Table 1). The caloric density was determined by the conversion factors of $4 \mathrm{kcal} / \mathrm{g}$ for carbohydrates and proteins and $9 \mathrm{kcal} / \mathrm{g}$ for total lipids. The diets were prepared every 15 days, packed in polyethylene bags, and stored at $-20{ }^{\circ} \mathrm{C}$. The group-specific diets and distilled water were offered ad libitum during the experimental period.

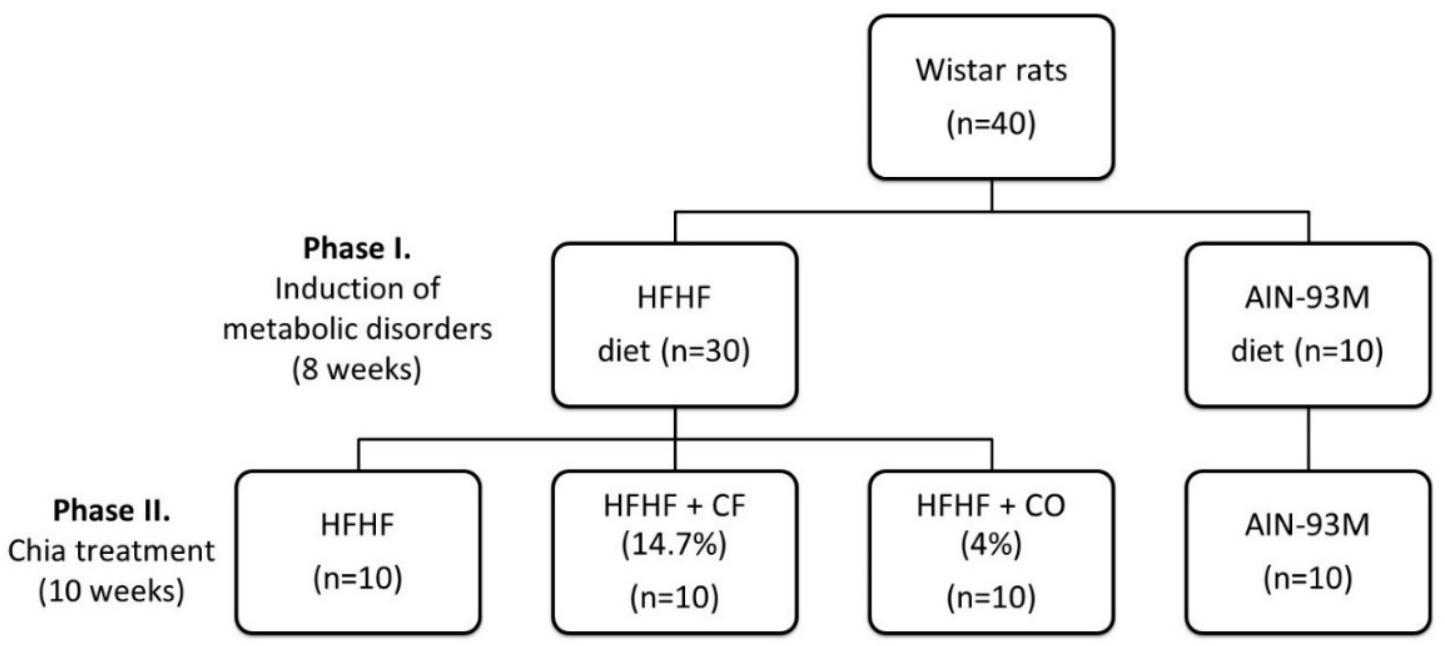

Figure 1. Experimental design. Phase I: Animals were fed a high-fat and high-fructose (HFHF) diet $(n=30)$ containing $4 \%(w / w)$ soybean oil, 31\% $(w / w)$ lard and $20 \%$ fructose $(w / w)$, or an AIN-93M diet $(n=10)$ for eight weeks. In the chia treatments (phase II), the HFHF group was divided into three groups $(n=10)$ : HFHF diet: the animals kept the HFHF diet; chia flour (CF) treatment group: HFHF diet with $4 \%$ of soybean oil replaced by chia flour lipid (14.7\% of chia flour); and chia oil (CO) treatment group: HFHF diet with $4 \%$ of soybean oil replaced by $4 \%$ of chia oil for ten weeks; and the AIN-93M group: the animals kept the AIN-93M diet for ten weeks.

Table 1. Nutritional composition of experimental diets.

\begin{tabular}{lcccc}
\hline Ingredients (g/kg of Diet) & AIN93-M & HFHF & Chia Flour & Chia Oil \\
\hline Albumin * & 136.4 & 136.4 & 101.8 & 136.4 \\
\hline Dextrinized starch & 155 & 45 & 45.4 & 45 \\
\hline Corn starch & 463.5 & 135 & 116.8 & 135 \\
\hline Sucrose & 100 & 28.6 & 29.3 & 28.6 \\
\hline Fructose & - & 200 & 200 & 200 \\
\hline Soybean oil & 40 & 40 & - & - \\
\hline Chia seed & - & - & 147.3 & - \\
\hline Chia oil & - & - & 310 & 40 \\
\hline Lard & - & 310 & - & 310 \\
\hline Microcristalline cellulose & 55.8 & 55.8 & 35 & 35.8 \\
\hline Mineral mix & 35 & 35 &
\end{tabular}


Table 1. Cont.

\begin{tabular}{|c|c|c|c|c|}
\hline Ingredients (g/kg of Diet) & AIN93-M & HFHF & Chia Flour & Chia Oil \\
\hline Vitamin mix & 10 & 10 & 10 & 10 \\
\hline L-cystine & 1.8 & 1.8 & 1.8 & 1.8 \\
\hline \multirow[t]{2}{*}{ Choline bitartrate } & 2.5 & 2.5 & 2.5 & 2.5 \\
\hline & \multicolumn{4}{|c|}{ Nutritional composition } \\
\hline \multicolumn{5}{|l|}{ Macronutrients } \\
\hline Carbohydrates (\%) & 77.4 & 30.1 & 31 & 30.1 \\
\hline Protein & 12.9 & 9.1 & 9.2 & 9.1 \\
\hline Lipids & 9.7 & 59.8 & 60.4 & 59.8 \\
\hline Energetic density (kcal/g) & 3.71 & 5.26 & 5.21 & 5.26 \\
\hline \multicolumn{5}{|l|}{ Fatty acids $(\mathrm{g} / \mathrm{kg})^{* *}$} \\
\hline Linoleic (C18:2n-6) & 20.2 & 58.8 & 46.5 & 46.5 \\
\hline$\alpha$-Linolenic (C18:3n-3) & 3.3 & 10.2 & 31.8 & 31.8 \\
\hline$n-6 / n-3$ ratio & $6.12: 1$ & $5.77: 1$ & $1.46: 1$ & $1.46: 1$ \\
\hline \multicolumn{5}{|c|}{$\begin{array}{l}\text { Experimental diets [16]: AIN93-M: standard rodent diet; and high-fat and high-fructose (HFHF); chia flour (CF): } \\
\text { HFHF with } 4 \% \text { of soybean oil replaced by chia flour lipid (14.7\% of chia flour); and chia oil (CO): HFHF diet with } \\
4 \% \text { of soybean oil replaced by } 4 \% \text { of chia oil for ten weeks. }{ }^{*} \text { Amount was calculated based on protein content } \\
\text { equal to } 88 \% \text { to provide } 12 \mathrm{~g} \text { protein } / 100 \mathrm{~g} \text { of diet. }{ }^{* *} \text { Fatty acids expressed in } \mathrm{g} / \mathrm{kg} \text { diet and determined by gas } \\
\text { chromatography (Figure } 2 \mathrm{~B}) \text {. }\end{array}$} \\
\hline
\end{tabular}

A

\begin{tabular}{lc}
\hline Components & $\begin{array}{c}\text { Content } \\
(\mathbf{g} / \mathbf{1 0 0 g})\end{array}$ \\
\hline Carbohydrates & 3.2 \\
Protein & 20.7 \\
Lipids & 27.1 \\
Saturated fat & 2.8 \\
Monounsaturated Fats & 2.0 \\
Polyunsaturated Fats & 22.3 \\
Total dietary fiber & 37.9 \\
Soluble dietary fiber & 3.4 \\
Insoluble Dietary Fiber & 34.5 \\
Moisture & 6.9 \\
Ash & 4.1 \\
Total phenolic (mg GAE/g) & 1.4 \\
DPPH $(\mu$ mol trolox/g) & 4.4 \\
\hline
\end{tabular}

B

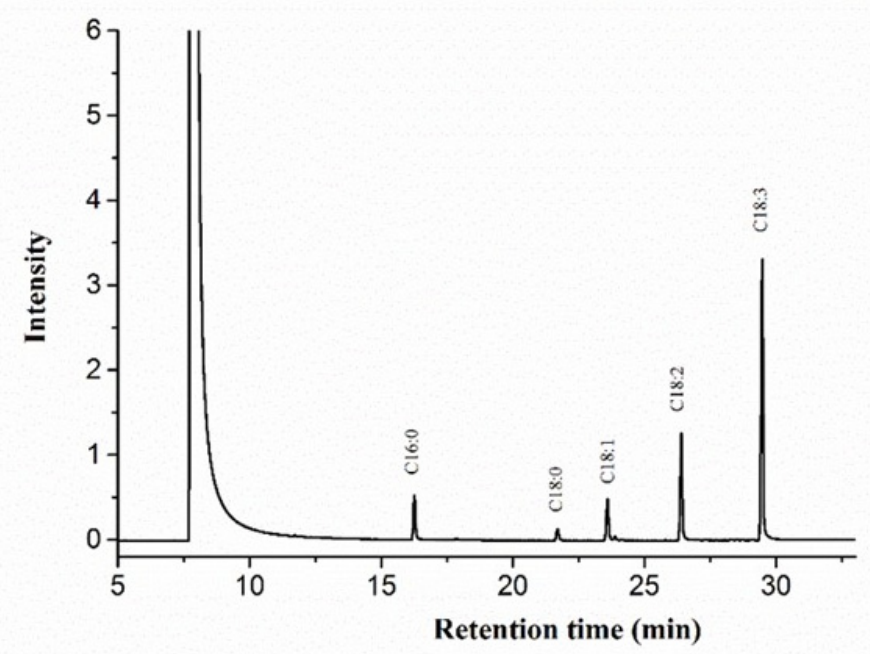

Figure 2. (A) Chemical characterization of chia flour. (B) Chia oil chromatogram with identification of fatty acids: P1: palmitic acid (C16:0, 7.6\%); P2: stearic acid (C18:0, 2.7\%); P3: oleic acid (C18:1, 7.5\%); P4: linoleic acid (C18:2, 19.9\%); and P5: alpha linolenic acid (C18:3, 62.3\%). In total, 10.3\% of fatty acids are saturated, $7.5 \%$ monounsaturated, and $82.2 \%$ polyunsaturated.

\subsubsection{Food Intake, Biometric Parameters, and Euthanasia}

The food intake and body weight were measured weekly. At the end of phase II, after ten weeks of the experiment, the naso-anal length (NAL) was measured by the Lee index, calculated using the equation: $\sqrt[3]{\mathrm{b} . \mathrm{w} \cdot(\mathrm{g})} / \mathrm{NAL}(\mathrm{cm}) \times 1000$.

At the end of the experiment, the animals were exposed to isoflurane general inhalation anesthesia (Isoforine, Cristália ${ }^{\circledR}$, São Paulo, Brazil), and then the euthanasia was performed by exsanguination through cardiac puncture. The blood was immediately collected by cardiac puncture (no fasting period), and centrifuged at $1006 \times g$ for $10 \mathrm{~min}, 4{ }^{\circ} \mathrm{C}$ (Hettich 
Universal 320 R, São Paulo, Brazil) for the biochemical analysis. The liver was rapidly collected, weighed, and a liver fragment was dissected and immersed in $10 \%$ formaldehyde. The remaining organ was immediately frozen in liquid nitrogen, and then stored at $-80{ }^{\circ} \mathrm{C}$ for further analyses. The hepatosomatic index was calculated using the following equation: liver weight $(\mathrm{g}) / \mathrm{b}$. w. $(\mathrm{g}) \times 100$.

\subsection{Biochemical Analysis}

The blood glucose and TG concentrations were measured by handheld monitors Accu-Chek ${ }^{\circledR}$, and Accutrend ${ }^{\circledR}$ GCT, respectively (Roche, Diabetes Care Ltd., São Paulo, Brazil), by the caudal vein puncture after ten weeks. The plasma was used to measure the concentrations of aspartate aminotransferase (AST), alanine aminotransferase (ALT), and uric acid using commercially available kits (Bioclin ${ }^{\circledR}$, Belo Horizonte, Brazil) by BS-200 Chemistry Analyzer, Bioclin ${ }^{\circledR}$.

\subsection{Gene Expression in the Liver}

The mRNA expression levels of genes related to lipogenesis: Srebf1 (sterol regulatory element binding transcription factor 1), and fatty acid oxidation: Cpt1a (carnitine palmitoyltransferase I) and Adipor2 (adiponectin receptor 2) were evaluated in the liver by quantitative reverse transcriptase-polymerase chain reaction (RT-qPCR). Total RNA extraction was performed using Trizol Reagent (Invitrogen, CA, USA). The quantification of extracted mRNA was performed by a spectrophotometer (Multiskan ${ }^{\mathrm{TM}}$ GO spectrophotometer, Thermo Fisher Scientific; Waltham, MA, USA). An M-MLV Reverse Transcriptase Kit (Invitrogen, CA, USA) was used for cDNA synthesis. The gene expression relative quantification was performed by AB StepOne Real-Time PCR System equipment and Fast SYBR Green Master Mix (Applied Biosystems, Waltham, MA, USA) reagent. The initial parameters used were $20 \mathrm{~s}$ at $95^{\circ} \mathrm{C}$, then 40 cycles of $3 \mathrm{~s}$ at $95^{\circ} \mathrm{C}$, and lastly $30 \mathrm{~s}$ at $60^{\circ} \mathrm{C}$ for annealing and extension. The primers used for amplification are listed as follows: Srebf1: CGC TAC CGT TCC TCT ATC AAT GAC (Forward); AGT TTC TGG TTG CTG TGC TGT AAG (Reverse); Cpt1a: GTA AGG CCA CTG ATG AAG GAA GA (Forward); ATT TGG GTC CGA GGT TGA CA (Reverse); Adipor2: CAT GTT TGC CAC CCC TCA GTA (Forward); ATG CAA GGT AGG GAT GAT TCC A (Reverse), and the housekeeping gene GAPDH (glyceraldehyde-3-phosphate dehydrogenase): AGG TTG TCT CCT GTC ACT TC (Forward); CTG TTG CTG TAG CCA TAT TC (Reverse). The primers (Sigma-Aldrich, São Paulo, Brazil) were designed by using the Primer 3 Plus program.Gene expression was calculated using the 2-Delta-Delta $C(\mathrm{~T})\left(2^{-\Delta \Delta \mathrm{Ct}}\right)$ method [23], by using GAPDH as endogenous control, and the HFHF group as the control normalized to 1 .

\subsection{Determination of Pro and Anti-Inflammatory Liver Proteins}

Pro-inflammatory proteins: TNF (88-7340-88), (Fisher Scientific, Vienna, Austria); TLR4

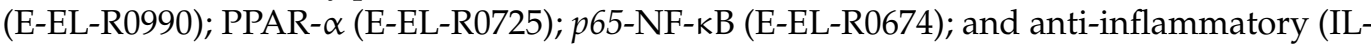
10: E-EL-R0016) (Elabscience, Houston, TX, USA) were determined by enzyme-linked immunosorbent assay (ELISA) kits for rats. To quantify the above-mentioned proteins, the liver homogenate was prepared according to NE-PER Nuclear and Cytoplasmic Extraction Reagents Kit (code 78835; Thermo Scientific, Vienna, Austria), except for IL-10, where $200 \mathrm{mg}$ of liver tissue was macerated with $50 \mathrm{mM}$ phosphate buffer containing $1 \mathrm{mM}$ EDTA $\left(\mathrm{pH} 7.4\right.$ ) and centrifugated at $12,000 \times g, 4{ }^{\circ} \mathrm{C}$ for $10 \mathrm{~min}$. The ELISA 96-well plates from the ELISA kits were precoated according to specific antibodies to each specific kit. The optical density was performed using the Multiskan ${ }^{\mathrm{TM}} \mathrm{GO}$ spectrophotometer (Thermo Fisher Scientific; Waltham, MA, USA), with wavelength ( $\mathrm{nm})$, and results expressed according to each kit. The data were normalized to total liver protein calculated by the Bradford method [24]. 


\subsection{Evaluation of Oxidative Stress}

The total antioxidant capacity (TAC) of the liver and plasma, the activity of antioxidant enzyme superoxide dismutase (SOD), and the nitric oxide (NO) lipid peroxidation biomarker were evaluated in the liver. The total liver protein [24] was used to express the results of SOD concentrations. To obtain liver homogenate, $200 \mathrm{mg}$ of liver tissue was macerated with $50 \mathrm{mM}$ phosphate buffer containing $1 \mathrm{mM}$ EDTA ( $\mathrm{pH}$ 7.4), and centrifugated at $12,000 \times g, 4{ }^{\circ} \mathrm{C}$ for $10 \mathrm{~min}$. The supernatant was recovered and stored at $-80{ }^{\circ} \mathrm{C}$.

\subsubsection{Total Antioxidant Capacity}

TAC was evaluated in the liver homogenate and plasma samples following a commercial antioxidant assay kit (Sigma-Aldrich, St. Louis, MO, USA). A volume of $10 \mu \mathrm{L}$ of each sample was transferred to a 96-well plate, followed by the addition of $20 \mu \mathrm{L}$ of a myoglobin-containing solution, and $150 \mu \mathrm{L}$ of 2,2'-azino-bis (3-ethylbenzothiazoline-6sulfonic acid substrate (ABTS). The plate was incubated for $5 \mathrm{~min}$ at room temperature. Then, $100 \mu \mathrm{L}$ of stop solution was added to each well, and absorbance was measured at $450 \mathrm{~nm}$ (Multiskan ${ }^{\mathrm{TM}}$ GO spectrophotometer, Thermo Fisher Scientific; Waltham, MA, USA). The results were expressed as nM Trolox equivalents.

\subsubsection{Superoxide Dismutase}

SOD activity was quantified in relative units as the amount of enzyme required to inhibit $50 \%$ of pyrogallol oxidation under test conditions [25]. The absorbance was measured at $570 \mathrm{~nm}$ (Multiskan ${ }^{\mathrm{TM}}$ GO spectrophotometer, Thermo Fisher Scientific; Waltham, MA, USA), and the results were expressed as units of SOD activity/mg of liver protein.

\subsubsection{Nitric Oxide}

Fifty microliters of liver homogenate was mixed with solutions A (1\% sulfanilamide in $2.5 \%$ orthophosphoric acid $\left(\mathrm{H}_{3} \mathrm{PO}_{4}\right)$ and $\mathrm{B}(0.1 \%$ naphthyl 1 ethylene diamide dihydrochloride in $\left.2.5 \% \mathrm{H}_{3} \mathrm{PO}_{4}\right)(1: 1)$, incubated in the dark for $10 \mathrm{~min}$. The microtiter plate was read at $570 \mathrm{~nm}$ (Multiskan ${ }^{\mathrm{TM}}$ GO spectrophotometer, Thermo Fisher Scientific; Waltham, MA, USA) [26]. The NO concentration was calculated according to a standard curve ranging from 100 to $0 \mu \mathrm{M}$ and the results were expressed in $\mu \mathrm{mol}$.

\subsection{Liver Histomorphometry}

Liver tissue fragments were dissected and fixed in $10 \%$ formaldehyde for $48 \mathrm{~h}$. The material was dehydrated using ethanol and embedded in historesin (Leica ${ }^{\circledR}$, Wetzlar, Germany). A semi-automatic rotary microtome (Leica ${ }^{\circledR} \mathrm{M} 2255$ ) and glass knives $\left(\right.$ Leica $^{\circledR}$ ) were used for semi-serial cuts $3 \mu \mathrm{m}$ thick, respecting the distance of 12 cuts between them. The images of the sections were taken under a bright field microscope (Olympus AX 70 TRF, Tokyo, Japan) with 20X objective. The inflammatory infiltrates and lipid vesicles were counted in the photographs from the sections stained with Gomori Trichrome using the Image ${ }^{\circledR} 1.48 \mathrm{v}$ (National Institutes of Health, Bethesda, MD, USA) software. In each histological field, a 266-point reticle was used until the sum of 1064 points per animal $(n=8)$ [27]. Picrosirius red staining was used to measure type I, III, and total collagen with a polarizing filter. The degree of liver steatosis was assessed quantitatively according to the 5-degree scale: Grade 0, if the percentage of fat was absent or $<5 \%$; Grade 1 , if $\geq 5 \%$ and $<25 \%$; Grade 2 , if $\geq 25 \%$ and $<50 \%$; Grade 3 , if $\geq 50 \%$ and $<75 \%$; and Grade 4 , if $\geq 75 \%$ [28]. The NAFLD activity score (NAS) was calculated based on the individual steatosis scores (0-3 points), lobular inflammation ( $0-3$ points), and hepatocyte ballooning (0-2 points) in a blinded manner to assess the severity of NAFLD. A score greater than or equal to five was considered NASH [29]. 


\subsection{Statistical Analyses}

The Shapiro-Wilk test was used to evaluate normality data. Data were expressed as average \pm standard deviation. The parametric data were evaluated by the one-way analysis of variance (ANOVA) and Newman-Keuls and Tukey (gene expression) as post-hoc tests to compare differences among groups. Kruskal-Wallis followed by Dunn's post-hoc test was used for the non-parametric data. A significance level of 5\% was considered. The statistical analyses and graphs were performed using GraphPad Prism software version 7.0 (San Diego, CA, USA).

\section{Results}

\subsection{Chemical Composition of Chia}

The chia chemical composition is depicted in Figure 2A. Among chia's oil lipids, 10.3\% were saturated, $7.5 \%$ monounsaturated, and $82.2 \%$ polyunsaturated. Regarding the fatty acid profile, 62.3\% were alpha-linolenic acid (ALA) (C18:3), 19.9\% linoleic acid (C18:2), 7.6\% palmitic acid (C16:0), 7.5\% oleic acid (C18: 1), and 2.7\% stearic acid (C18:0) (Figure 2B). The peroxide value of chia oil was $1.9 \mathrm{mqE}$, and its acidity was $3.8 \mathrm{mg} \mathrm{KOH} / \mathrm{g}$.

\subsection{Effect of Chia on Food Intake, and Murinometric Measures}

The addition of $\mathrm{CO}$ and $\mathrm{CF}$ into the HFHF diet decreased the omega6:omega3 ratio from 5.77:1 to 1.46:1, while the AIN93-M diet showed a 6.17:1 ratio. The AIN93-M group showed the highest food intake (Figure 3A). The daily consumption of chia flour was $2.14 \mathrm{~g} \pm 0.14$ (0.48 $\mathrm{g}$ of omega-3), and chia oil was $0.58 \mathrm{~g} \pm 0.04$ (0.46 $\mathrm{g}$ of omega-3) (Figure 3B). The highest final body weight was observed in the HFHF group. The addition of chia oil was able to reduce body weight at the AIN93-M level (Figure 3C). The Lee index was higher in the HFHF group, and chia flour and oil were able to reduce this parameter (Figure 3D).

\subsection{Effect of Chia on Biochemical Parameters}

Blood glucose and TG concentrations increased in the HFHF group and CO intake was able to reduce both parameters. The HFHF diet increased AST, ALT and uric acid levels, but CF and CO diets did not significantly reduce these levels (Table 2).

Table 2. Effects of chia on biochemical parameters.

\begin{tabular}{ccccc}
\hline \multicolumn{5}{c}{ Experimental Diets } \\
\hline Parameters & AIN-93M & HFHF & CF & CO \\
\hline Glucose (mg/dL) & $82.1 \pm 12.1^{\mathrm{b}}$ & $100.9 \pm 7.8^{\mathrm{a}}$ & $89.17 \pm 2 \pm 11.9^{\mathrm{ab}}$ & $82.7^{\mathrm{b}} \pm 11.5^{\mathrm{b}}$ \\
TG (mg/dL) & $117.5 \pm 17.1^{\mathrm{b}}$ & $147.8 \pm 21.6^{\mathrm{a}}$ & $130.4 \pm 7.8^{\mathrm{ab}}$ & $115.8^{\mathrm{b}} \pm 7.4^{\mathrm{b}}$ \\
AST (U/L) & $98.5 \pm 23.7^{\mathrm{b}}$ & $150.7 \pm 30.3^{\mathrm{a}}$ & $172.0^{\mathrm{a}} \pm .^{\mathrm{a}}$ & $172.9^{\mathrm{a}} \pm 12.1^{\mathrm{a}}$ \\
ALT (U/L) & $29.0 \pm 11.1^{\mathrm{b}}$ & $51.3 \pm 16.9^{\mathrm{a}}$ & $39.7 \pm 6.3^{\mathrm{ab}}$ & $52.1 \pm 17.7^{\mathrm{a}}$ \\
Uric acid (mg/dL) & $1.3 \pm 0.7^{\mathrm{b}}$ & $3.4 \pm 2.4^{\mathrm{a}}$ & $2.4 \pm 1.2^{\mathrm{ab}}$ & $1.7 \pm 1.2^{\mathrm{ab}}$ \\
\hline
\end{tabular}

Animals fed AIN93-M: standard rodent diet; HFHF: high-fat and high-fructose; chia flour (CF): HFHF with $4 \%$ of soybean oil replaced by chia flour lipid (14.7\% of chia flour); and chia oil (CO): HFHF diet with $4 \%$ of soybean oil replaced by $4 \%$ of chia oil for 10 weeks. Values are represented by average and standard deviation $(n=10)$ The difference between the averages was analyzed by the one-way ANOVA test followed by the Newman-Keuls post-hoc test. Different letters indicate significant statistic difference $(p<0.05)$. ALT: alanine aminotransferase; AST: aspartate aminotransferase; TG: triglycerides.

\subsection{Gene Expression in the Liver}

CF downregulated Srebf1 gene expression (Figure 4A), as well as upregulated Cpt1a (Figure 4B). Otherwise, only CO upregulated Adipor2 gene expression (Figure 4C). 
A

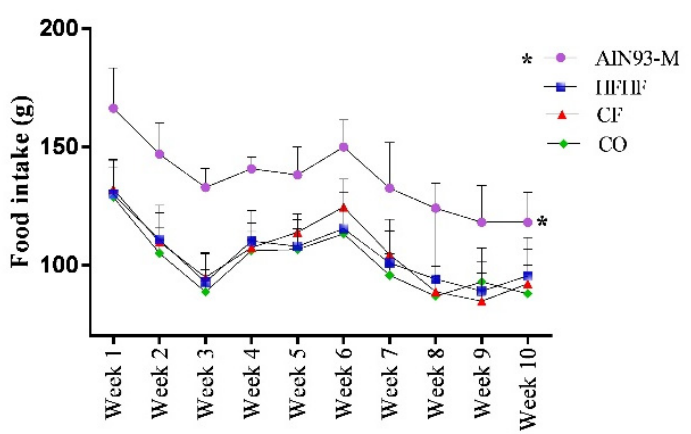

C

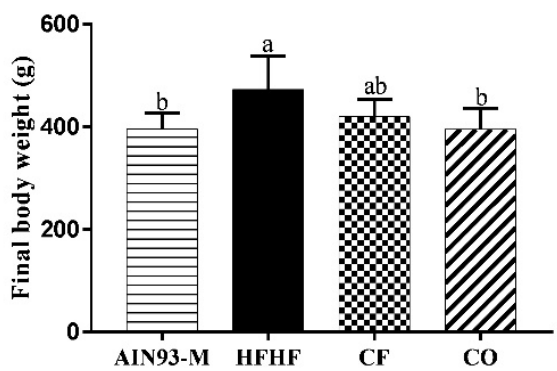

B

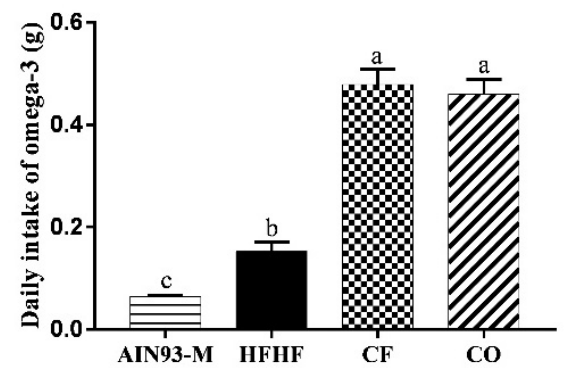

D

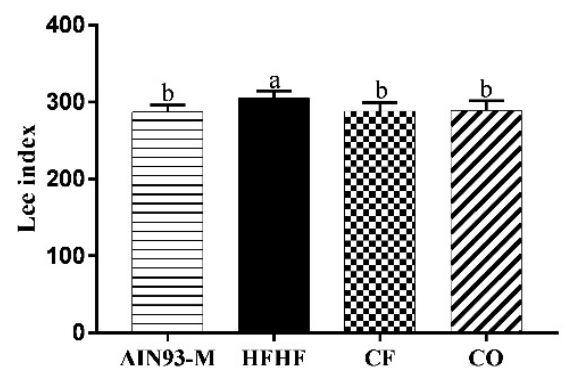

Figure 3. (A) Food intake (weekly); (B) Daily intake of omega-3; (C) Final body weight at the end of 10 weeks; (D) Lee index. The animals were fed the following diets: AIN93-M: standard rodent diet; HFHF: high-fat and high-fructose; chia flour (CF): HFHF with $4 \%$ of soybean oil replaced by chia flour lipid (14.7\% of chia flour); and chia oil (CO): HFHF diet with $4 \%$ of soybean oil replaced by $4 \%$ of chia oil for 10 weeks. Values are represented by average and standard deviation $(n=10)$. The difference between the averages was analyzed by the one-way ANOVA test followed by the Newman-Keuls post-hoc test, except for daily intake of omega-3 (non-parametric data) performed by the Kruskal-Wallis test and the post-hoc Dunn's test. * Food intake (A) indicates statistical difference between AIN93-M and the other groups. Different letters indicate significant statistic difference $(p<0.05)$.

A

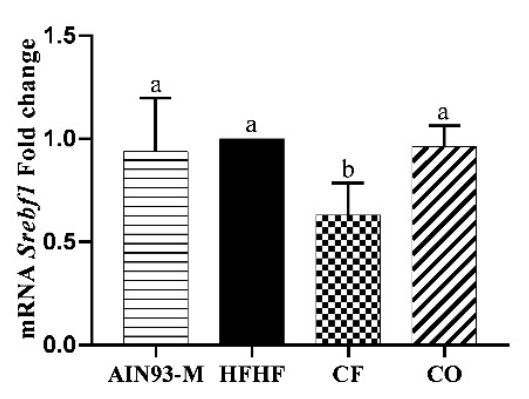

B

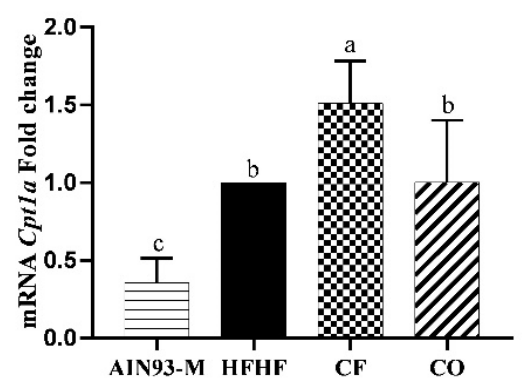

C

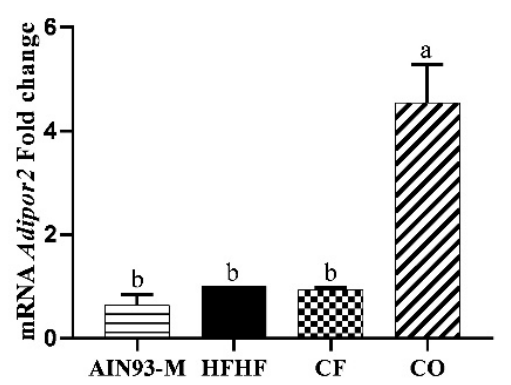

Figure 4. (A) Srebf1: sterol regulatory element-binding transcription factor 1; (B) Cpt1a: carnitine palmitoyltransferase 1a; (C) Adipor2: adiponectin receptor 2. The animals were fed diets: AIN93-M: standard rodent diet; HFHF: high-fat and high-fructose; chia flour (CF): HFHF with $4 \%$ of soybean oil replaced by chia flour lipid (14.7\% of chia flour); and chia oil (CO): HFHF diet with $4 \%$ of soybean oil replaced by $4 \%$ of chia oil for 10 weeks. Values are represented by average and standard deviation $(n=10)$. The difference between the averages was analyzed by the one-way ANOVA test followed by the Newman-Keuls post-hoc test. Different letters indicate significant statistic difference $(p<0.05)$. 


\subsection{Effect of Chia on Pro and Anti-Inflammatory Proteins in the Liver}

The HFHF diet increased TLR4 and TNF levels compared to the AIN93-M diet. The consumption of $\mathrm{CF}$ and $\mathrm{CO}$ did not decrease these proteins, although chia treatments showed a similar pattern to the AIN93-M levels (Figure 5A,B). Regarding p65-NF- $\mathrm{kB}$ (Figure 5C), PPAR- $\alpha$ (Figure 5D), IL-10 (Figure 5E) levels and inflammatory infiltrate (Figure 5F), there were no significant differences among groups.

A

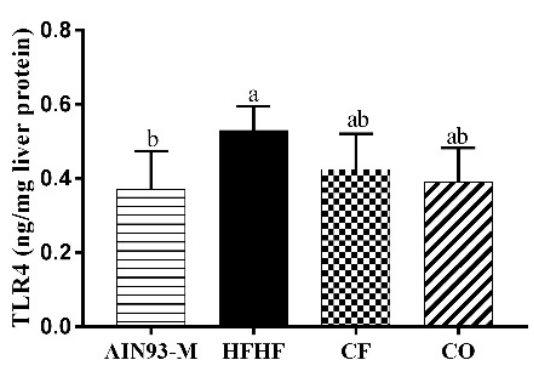

D

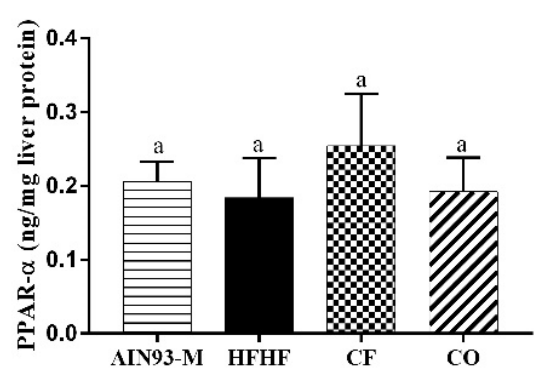

B

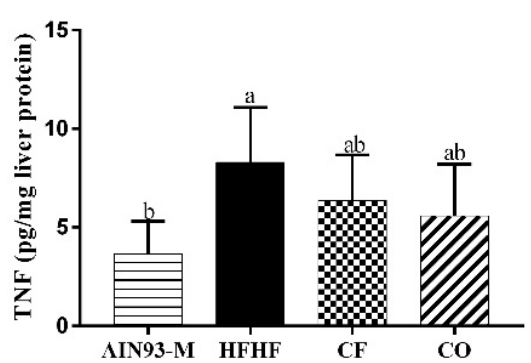

E

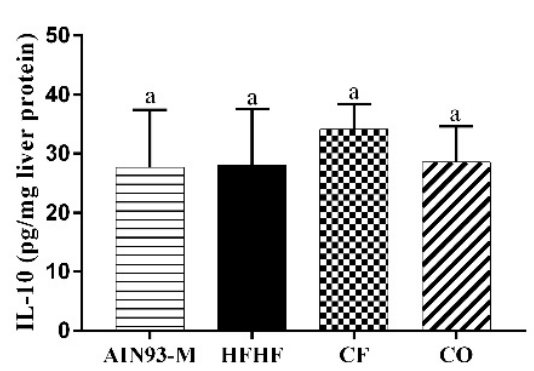

C
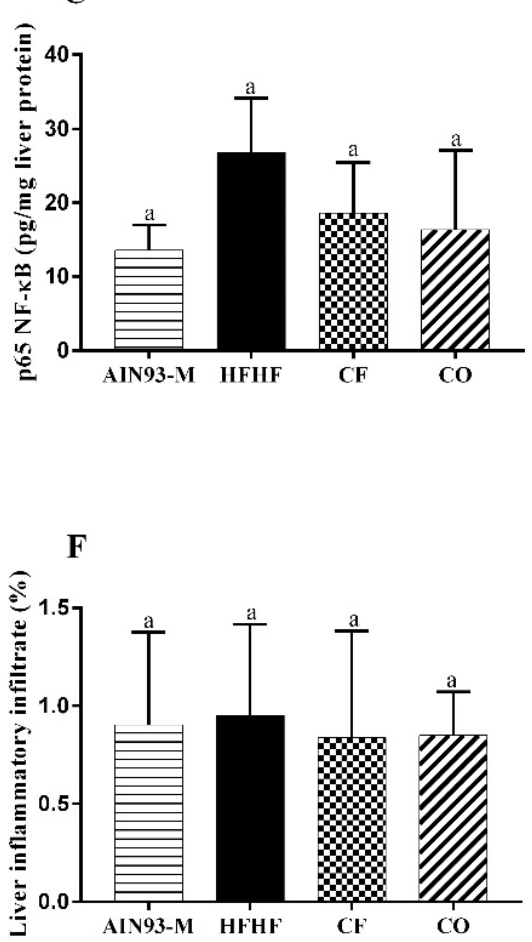

Figure 5. Effect of diets on inflammatory proteins and infiltrate in the liver at the end of 10 weeks. (A) Toll-like receptor 4 (TLR4); (B) tumor necrosis factor (TNF); (C) p65-nuclear factor kappa B transcriptional (NF-kB); (D) peroxisome proliferator-activated receptor alpha (PPAR- $\alpha$ ); (E) interleukin 10 (IL-10); (F) liver inflammatory infiltrate. The animals were fed diets: AIN93-M: standard rodent diet; HFHF: high-fat and high-fructose; chia flour (CF): HFHF with $4 \%$ of soybean oil replaced by chia flour lipid (14.7\% of chia flour); and chia oil (CO): HFHF diet with $4 \%$ of soybean oil replaced by $4 \%$ of chia oil for 10 weeks. Values are represented by average and standard deviation $(n=10)$. The difference between the averages was analyzed by the one-way ANOVA test followed by the Newman-Keuls post-hoc test. Different letters indicate significant statistic difference $(p<0.05)$.

\subsection{Effect of Chia on Oxidative Stress}

No significant difference was observed in plasma TAC among experimental groups (Figure 6A). The analyses in the liver demonstrated that the chia consumption positively affected the TAC, restored the SOD activity, and reduced NO levels (Figure 6B-D). 
A

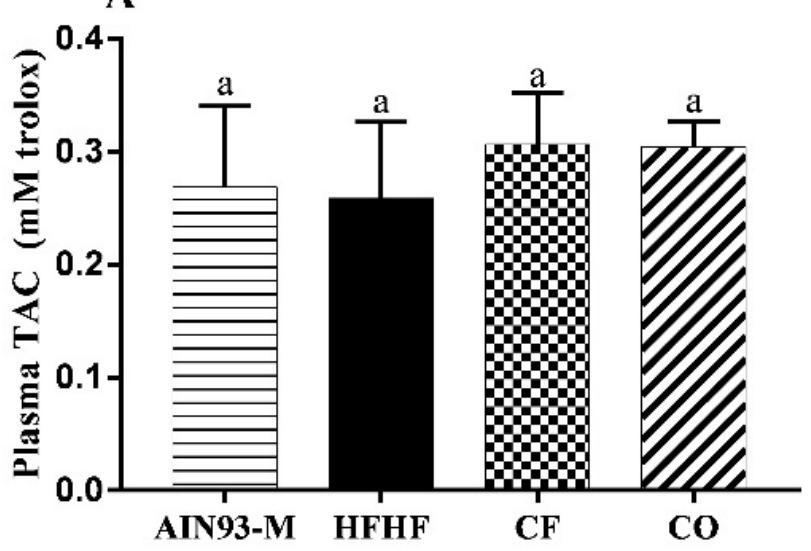

C

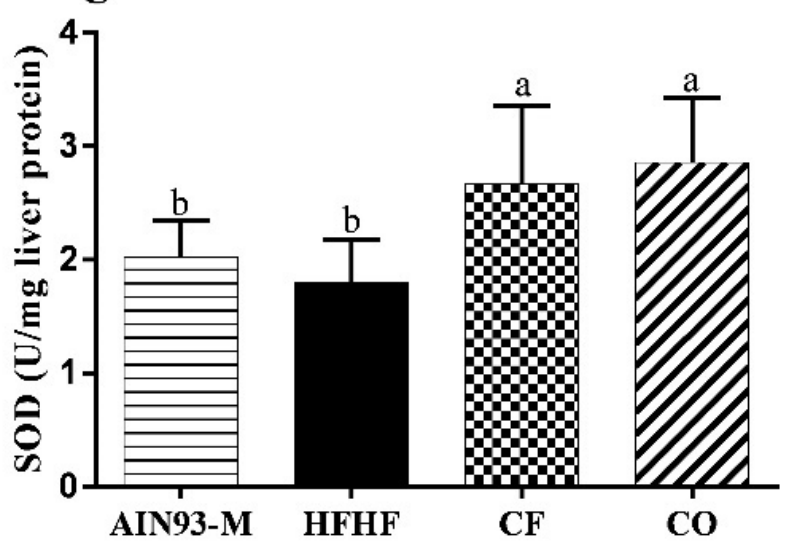

B

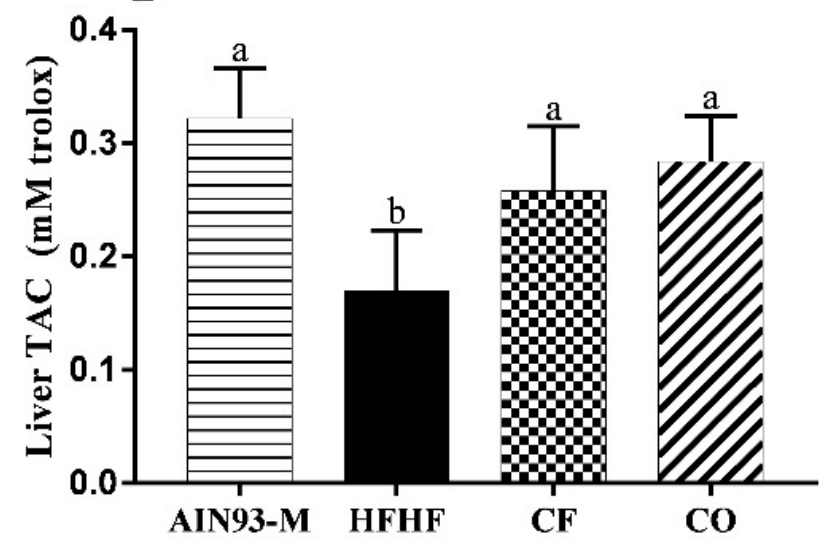

D

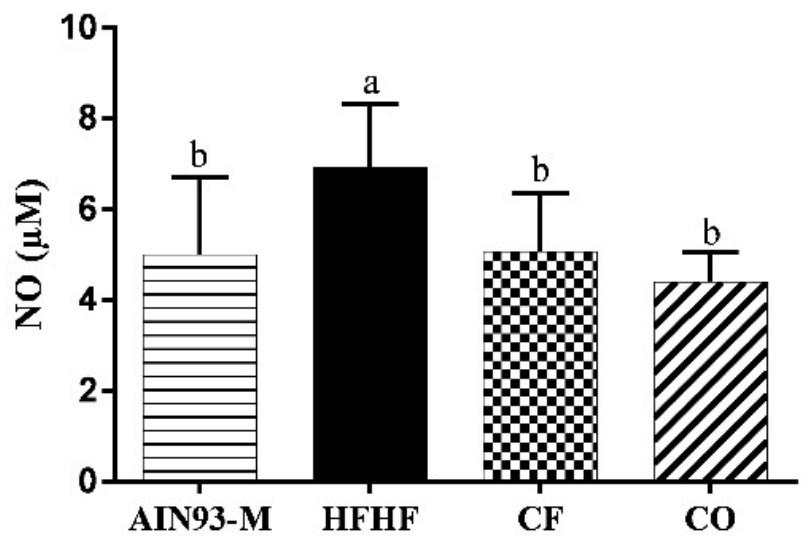

Figure 6. Effect of diets on oxidative stress. (A) plasma total antioxidant capacity (TAC); (B) liver total antioxidant capacity (TAC); (C) superoxide dismutase (SOD); and (D) nitric oxide (NO) in the liver. The animals were fed diets: AIN93-M: standard rodent diet; HFHF: high-fat and high-fructose; chia flour (CF): HFHF with $4 \%$ of soybean oil replaced by chia flour lipid (14.7\% of chia flour); and chia oil (CO): HFHF diet with $4 \%$ of soybean oil replaced by $4 \%$ of chia oil for 10 weeks. Values are represented by average and standard deviation $(n=10)$. The difference between the averages was analyzed by the one-way ANOVA test followed by the Newman-Keuls post-hoc test. Different letters indicate significant statistic difference $(p<0.05)$.

\subsection{Effect of Chia on Liver's Biometric and Histomorphometry Parameters}

Animals from the AIN93-M group retained 17.9\% of lipid droplets in the liver, classified as liver steatosis grade 1 (Figure 7A), and the animals fed the HFHF diet showed liver steatosis grade $2(28.7 \%$-Figure $7 \mathrm{~B})$. CF and CO improved liver steatosis compared to the HFHF group ( $\mathrm{CF}-15.5 \%$ and $\mathrm{CO}-12.9 \%$ ) (Figure $7 \mathrm{C}, \mathrm{D})$. Among the groups, there was no significant difference in liver weight, hepatosomatic index (Figure 7E,F), and type I, III, and total collagen (data not shown). NAS was higher in the HFHF group (4.19), whereas AIN93-M, CF, and CO presented NAS of 2.68, 2.81, and 2.17, respectively (Figure $7 \mathrm{G}$ ). 

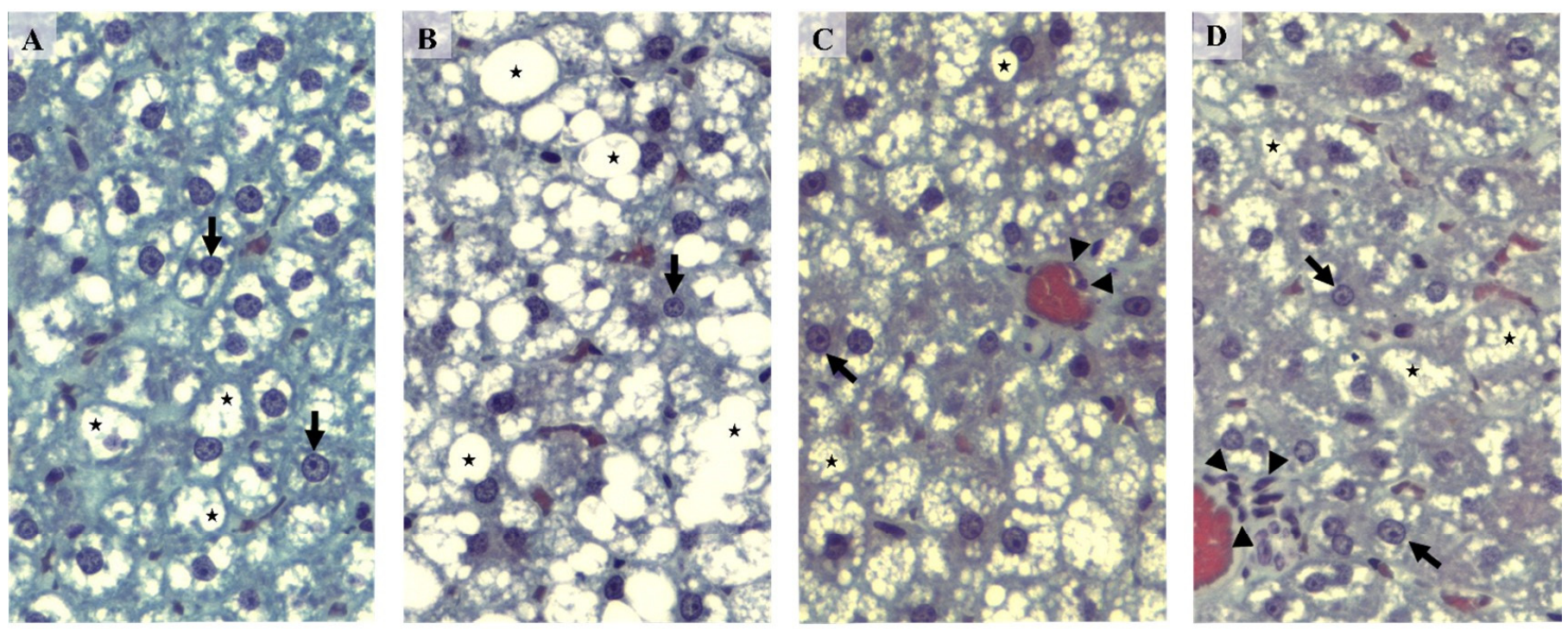

$\mathbf{E}$

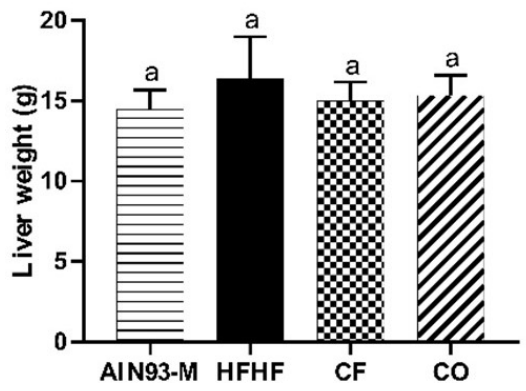

$\mathbf{F}$

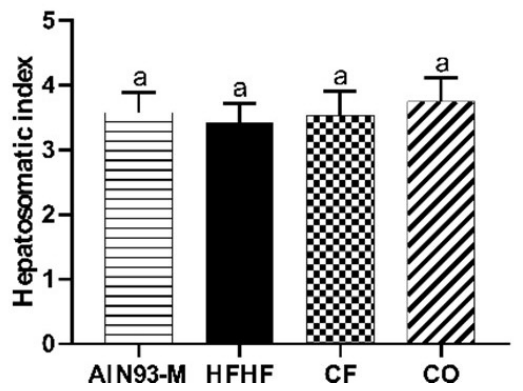

G

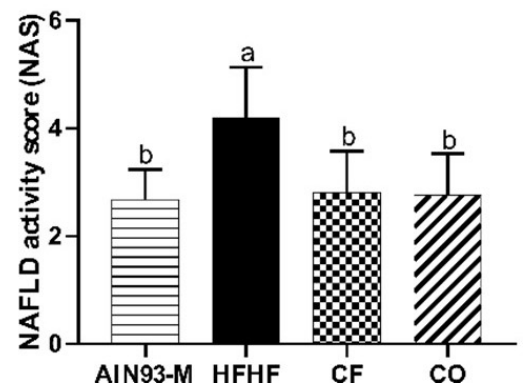

Figure 7. Representative histopathological photomicrographs of liver sections after 10 weeks od experiments in the groups: (A) AIN-93M (28.7\% of lipid droplets in the liver); (B) HFHF: $4 \%$ of soybean oil, 31\% lard, and 20\% fructose) (animals showed $17.9 \%$ of lipid droplets in the liver); (C) chia flour: HFHF with $4 \%$ soybean oil replaced by chia flour (CF) lipid (14.7\% of chia flour) $(15.5 \%$ of lipid droplets in the liver); (D) chia oil (CO): HFHF with $4 \%$ of soybean oil replaced by $4 \%$ of chia oil (12.9\% of lipid droplets in the liver); (E) liver weight; (F) hepatosomatic index; (G) NAFLD activity score (NAS). Gomori Trichrome Stain. $(\rightarrow)$ Hepatocyte nucleus; $(>)$ lipid vesicles; $(\star)$ blood vessels. Bar $=50 \mu \mathrm{m}$. Values of liver weight $(n=10)$, hepatosomatic index $(n=8)$, and NAS $(n=8)$ are represented by average and standard deviation The difference between the averages was analyzed by the one-way ANOVA test followed by the Newman-Keuls post-hoc test. Different letters indicate significant statistical differences $(p<0.05)$.

\section{Discussion}

The consumption of chia flour and chia oil improved liver steatosis and oxidative stress. In addition, flour and oil led to the downregulation and upregulation of genes involved in lipogenesis, and fatty acid oxidation, respectively. However, chia did not show significant effects on mitigating pro-inflammatory liver status in rats fed a high-fat and high-fructose (HFHF) diet. All these metabolic parameters evaluated in our study are recognized in NAFLD conditions.

Animals fed an HFHF diet demonstrated an unbalanced redox system evidenced by reduced TAC and increased NO levels in the liver. These findings could be explained by the lower antioxidants present in the HFHF diet, regarding its ingredients, impairing endogenous antioxidant levels. Moreover, long-term exposure to fructose and saturated fat provides a pro-oxidant environment by an increase in free fatty-acids oxidation, whereas lipid peroxidation leads to the production of lipotoxic 
species [30]. On the other hand, adding chia flour or chia oil into the HFHF diet improved the antioxidant system in the liver, observed by increased total antioxidant activity, increased SOD enzymatic activity levels, and reduced NO levels, which is a lipid peroxidation biomarker. Chia flour and oil contain antioxidant compounds, such as phenolic acids, flavonoids, peptides, vitamins (carotenoids and tocopherols), and minerals $[10,11,31,32]$, which could assist in increasing antioxidant activity. Our results agree with the literature indicating chia has antioxidant properties in animal models. As described elsewhere, Wistar rats fed a high-fat diet (HFD) enriched with $41.3 \%$ of chia flour for five weeks increased the SOD (liver) and CAT (plasma) activities [33].

The high consumption of lipogenic substrates, such as fructose, promotes de novo lipogenesis regulated mainly by Srebf1, a gene involved in lipid biosynthesis which increases lipid retention in the hepatocytes [8]. In our study, the animals that consumed the HFHF diet showed $28.7 \%$ of fat accumulation in hepatocytes, which confirms that saturated fat and fructose are highly lipogenic. The animals AIN-93M showed $17.9 \%$ of lipid retention in the liver. Although AIN93-M is considered a standard diet for rodents, $77.4 \%$ of carbohydrates in its composition can lead to up-regulated Srebf 1 expression and trigger de novo lipogenesis [34]. It demonstrates the need to reassess and modify the carbohydrate content in the AIN93-M standard diet. Chia flour showed downregulation on Srebf1, upregulation on Cpt-1a, and reduction of $46 \%$ on lipid droplets in the liver compared to the HFHF group. Cpt-1a is involved in the fatty acids oxidation pathway, acting on the translocation of long-chain fatty acids from the cytosol to the mitochondrial matrix [5]. A study administered $36.2 \%$ of chia seed added into a sucrose rich diet (SRD) (24 weeks), and SRD plus $20 \%$ of chia seed (20 weeks) to Wistar rats and verified an increase of CPT-1 levels in the cardiac muscle and liver, respectively [35,36], which is a gene involved in lipogenesis process. An HFHF diet with $4 \%$ of chia oil (six weeks) and $13.3 \%$ of chia seed increased the receptor- $\gamma$ coactivator 1-alpha (PGC-1 $\alpha$ ) protein levels in the skeletal muscle of Wistar rats, a biomarker involved in increasing beta-oxidation [37]. HFD plus 1.900 or $3.800 \mathrm{mg}$ of $\mathrm{CO} / \mathrm{kg}$ of body weight of mice for five weeks concomitantly reduced oxidative stress and liver steatosis [38]. While the dose of chia oil used in the mentioned study above is remarkably higher than our experiment, it can indicate that lower doses as used in our study are effective in reducing oxidative stress and liver fat content. Altogether, these findings indicate that chia act in different metabolic pathways assisting the reduction of metabolic liver disorders. The animals fed chia oil had upregulation on Adipor 2 gene expression in the liver, and reduction of $55 \%$ of liver lipid droplets compared to the HFHF group. In addition, chia oil was more efficient than chia flour in reducing blood glucose, plasma TG levels, and final body weight. The ADIPO-R2 is a receptor of adiponectin, an adipocytokine involved in lipid and glucose metabolism [39]. Although our present study did not quantify the levels of this protein, we hypothesize that the increased Adipor 2 expression may have played a key role in enhancing glucose uptake and inducing activation of pathways related to fatty acid oxidation. In our previous study, the addition of $4 \%$ of CO to Wistar rats fed the HFHF diet increased insulin sensitivity, recovering glucose metabolism by AMPK activation [16]. This enzyme can act on the lipid oxidation pathway, increasing mitochondrial beta-oxidation and consequent reduction of liver lipid droplets [40]. A study demonstrated that the administration of $0.15 \%$ of chia oil to male C57BL/ 6 mice for 45 days improved glucose metabolism [41,42]. Overall, our results demonstrate hepatoprotective properties of chia, attenuating the harmful effect caused by saturated fat and fructose and improving glucose uptake. 
The consumption of bioactive compounds such as omega-3 fatty acids and polyphenols can reduce the pro-inflammatory status and might lead to an anti-inflammatory effect [43]. One of these effects is the increase of PPAR- $\alpha$ levels. PPAR- $\alpha$ is a nuclear transcription factor that positively modulates the lipid metabolism acting as a regulator of free fatty acid oxidation, and its inactivation is also negatively involved with proinflammatory status, liver steatosis, mitochondrial dysfunction, and endoplasmic reticulum stress [44]. High levels of this protein can promote the inactivation and proteolytic degradation of $p 65-\mathrm{NF}-\mathrm{kB}$, and consequently inhibit pro-inflammatory processes [45]. Our study demonstrated that the HFHF diet induced liver inflammation, observed by TLR4, TNF, and $p 65-N F-B$ proteins levels, without statistical differences among the groups regarding PPAR- $\alpha$, IL-10 levels, and inflammatory infiltrates (Figure 5). Therefore, according to the results, we can claim that PPAR- $\alpha$ did not contribute to the reduction of liver steatosis. In addition, the consumption of chia flour and chia oil did not show any effect on IL-10 levels, an anti-inflammatory cytokine, as well as not reducing TLR4, $p 65 \mathrm{NF}-\mathrm{KB}$, and TNF protein levels. A study administered $0.15 \%$ of chia oil to rats fed HFD and there were no differences regarding plasma IL-10 [41]. The addition of $23.26 \%$ of chia flour into HFD ( $51 \%$ of fat) did not reduce NF-KB expression and TNF levels in female rat livers [46]. However, HFD plus $41.68 \%$ of chia flour offered to Wistar rats increased PPAR- $\alpha$ levels and reduced NF- $K B$ and TNF levels in the liver [33]. It possibly could be due to a greater chia flour content. We might not have observed chia's positive effect on liver inflammation due to the high fructose and saturated fat content in the HFHF diet, which led to a high pro-inflammatory state that may have blocked chia's effect in this signaling pathway. Chia did not reduce the liver enzymes AST and ALT or uric acid, markers of liver damage caused mainly by the high consumption of fructose. Type I, III, and total collagen indicate liver fibrosis, and in this study, we did not observe a significant difference in these parameters. Probably, the duration of the experiment period was insufficient to induce fibrosis in the animal's liver by the consumption of fructose. Concerning the NAFLD activity score, the highest NAS was observed in the HFHF group (Figure 7). Overall, according to our results, we can confirm that the HFHF diet induced metabolic disorders on the animal's liver such as increased lipogenesis, liver steatosis, oxidative stress, and inflammation in the liver, features present in NAFLD. Nevertheless, chia flour and oil contributed to ameliorating these metabolic disorders in the liver. The beneficial effects of chia on liver health were observed through different mechanisms, and it is not directly linked to the resolution of liver inflammation (Figure 8), which indicates that the improvement in inflammation may occur later. We believe that the physical-chemical differences between chia flour and chia oil can be responsible for the different outcomes observed in this study. The chia oil (rich in ALA, lipophilic compounds, tocopherols, and phenols) led to up-regulated Adipor 2 expression, which improved glucose metabolism by reducing blood glucose, TG levels, and body weight. It also reduced oxidative stress and liver steatosis. In turn, chia flour may decrease ALA bioavailability and other lipophilic compounds since lipid enzymes may be more exposed in the chia oil rather than in chia flour. It can impact its digestion, absorption, transport, metabolism, and bioavailability. Therefore, the major components present in chia flour;dietary fibers, phenolic compounds, and micronutrients can be responsible for the downregulation of Srebf1 combined with augmented Cpt1a expression, improvement of fatty acid oxidation and lipogenesis, as well as the redox system, and reduced liver steatosis. 


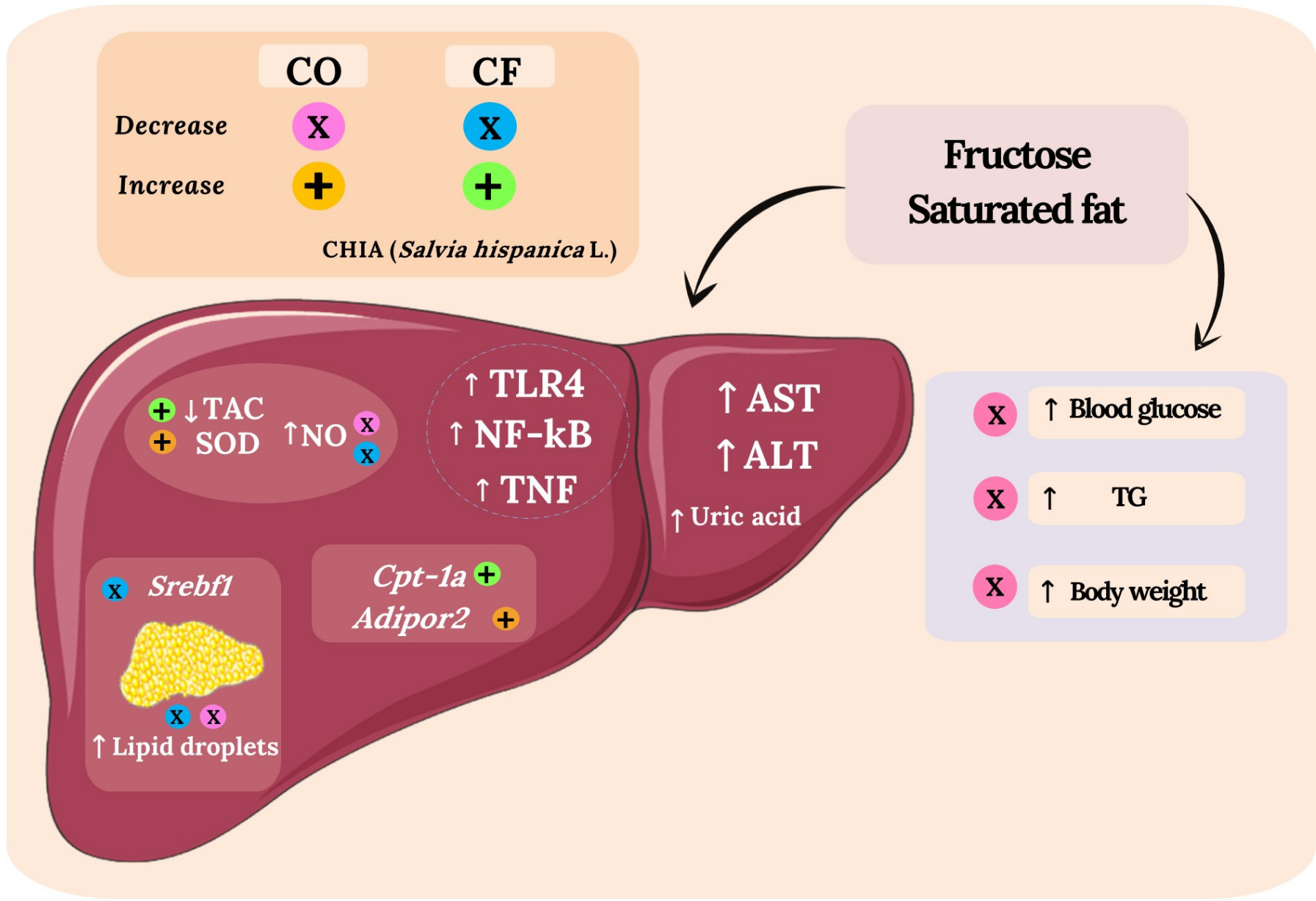

Figure 8. Metabolic disorders caused by the consumption of an HFHF diet, and the effects of chia flour (CF) and chia oil (CO) on the metabolic biomarkers evaluated in Wistar rats. The consumption of a high-fat and high-fructose (HFHF) diet caused metabolic disorders in the liver of the animals. The alterations were observed by the oxidant status, gene expression involved in lipogenesis, liver steatosis, and the activation of pro-inflammatory processes by increased TLR4, TNF, NF- $\mathrm{B}$, and protein levels in the liver. Furthermore, there was an increase in liver damage markers such as AST and ALT enzymes, and the uric acid concentrations, blood glucose, triglycerides (TG) levels, and body weight. The treatments with chia flour and chia oil increased SOD enzyme activity and reduced NO levels. The chia flour reduced lipogenesis and increased fatty acid oxidation observed by down-regulated Srebf1, and up-regulated Cpt1a, respectively, reducing liver steatosis. The chia oil up regulated Adipor2, a gene involved in lipid and glucose metabolism which decreased blood glucose, TG levels, liver steatosis, and body weight. No difference was observed in the PPAR- $\alpha$, p65-NF- $\mathrm{kB}$, and IL-10 proteins levels, demonstrating that the inflammation mitigation may occur later. Chia flour and chia oil added into the HFHF diet proved to be a relevant strategy to reduce metabolic disorders in the liver, parameters present in the NAFLD. Adipor2: adiponection receptor 2; ALT: alanine aminotransferase; AST: aspartate aminotransferase; CF: chia flour; CO: chia oil; Cpt1a: carnitine palmitoyltransferase 1a; HFHF: high-fat and high-fructose diet; NO: nitric oxide; $p 65-\mathrm{NF}-\kappa \mathrm{B}$ : nuclear factor kappa-B transcriptional factor; SOD: superoxide dismutase; Srebf1: sterol regulatory element binding transcription factor 1; TAC: total antioxidant capacity; TG: triglycerides; TLR4: Toll-like receptor 4; TNF: tumor necrosis factor. $\uparrow:$ increase; $\downarrow$ : decrease; Chia effects: X-pink color: chia oil (CO) reduced NO, liver steatosis, blood glucose, TG and body weight; X-blue color: chia flour $(\mathrm{CF})$ reduced NO, liver steatosis, and Srebf1 expression; + in orange color: chia oil (CO) increased liver TAC, SOD activity, and Adipor2 expression; + in green color: chia flour (CF) increased liver TAC, SOD activity, and Cpt1a expression. 


\section{Conclusions}

The inclusion of chia flour or oil into an unbalanced diet rich in saturated fat and fructose promotes beneficial effects on liver health by reducing metabolic disorders through the modulation of different mechanisms. The chia flour and oil restored the antioxidant system and increased fatty acid oxidation. Furthermore, chia flour modulated lipogenesis, and chia oil improved blood glucose, TG levels, and body weight. These results reflected on reducing the degree of liver steatosis. Chia did not demonstrate a direct link to reduce liver inflammation, therefore it did not contribute to mitigating pro-inflammatory liver status, which requires further studies. In general, chia consumption is an interesting strategy for liver metabolic disorders.

Author Contributions: Conceptualization, L.d.P.D.M., B.N.E., H.S.D.M., R.C.L.T. and H.H.M.H.; Formal analysis: L.d.P.D.M., B.N.E., R.C.L.T. and L.C.M.L.; Investigation: L.d.P.D.M., B.N.E., V.P.B.d.S.J., R.C.L.T., L.C.M.L. and R.R.C., Resources: H.S.D.M., V.d.S.D., F.A.R.d.B.; Data curation, writingoriginal draft preparation, L.d.P.D.M.; Writing-review and editing, L.d.P.D.M., B.N.E., V.d.S.D., H.H.M.H., F.A.R.d.B. and H.S.D.M.; Supervision, H.S.D.M. and R.C.L.T. All authors have read and agreed to the published version of the manuscript.

Funding: The authors would like to thank the National Council of Technological and Scientific Development (CNPq, Brazil) for Research Support (MCTIC/CNPq N ${ }^{\circ}$ 28/2018-Universal-406517/20185) and Research Productivity grants, the Coordination for the Improvement of Higher Education Personnel (CAPES, Brazil, code 001) and the Scholarship Research support (Master's degree-Luiza de Paula Dias Moreira) from the Fundação de Amparo à Pesquisa do Estado de Minas Gerais. (FAPEMIG-Nº 001/2017-APQ-02183-17, Demand Universal, Brazil).

Institutional Review Board Statement: The animal study protocol was approved by the Ethics Commission on Animal Use (CEUA) of the Universidade Federal de Viçosa (CEUA/UFV_protocol no. 89/2018; date of approval: 21 February 2019).

Data Availability Statement: Not applicable.

Conflicts of Interest: The authors declare no conflict of interest.

\section{References}

1. Muriel, P.; López-Sánchez, P.; Ramos-Tovar, E. Fructose and the Liver. Int. J. Mol. Sci. 2021, 22, 6969. [CrossRef]

2. Wong, W.-K.; Chan, W.-K. Nonalcoholic Fatty Liver Disease: A Global Perspective. Clin. Ther. 2021, 43, 473-499. [CrossRef] [PubMed]

3. Kanwal, F.; Kramer, J.R.; Li, L.; Dai, J.; Natarajan, Y.; Yu, X.; Asch, S.M.; El-Serag, H.B. Effect of Metabolic Traits on the Risk of Cirrhosis and Hepatocellular Cancer in Nonalcoholic Fatty Liver Disease. Hepatology 2020, 71, 808-819. [CrossRef] [PubMed]

4. Bawden, S.; Stephenson, M.; Ciampi, E.; Hunter, K.; Marciani, L.; Macdonald, I.; Aithal, G.; Morris, P.; Gowland, P. Investigating the effects of an oral fructose challenge on hepatic ATP reserves in healthy volunteers: A 31P MRS study. Clin. Nutr. 2016, 35, 645-649. [CrossRef]

5. Distefano, J.K. Fructose-mediated effects on gene expression and epigenetic mechanisms associated with NAFLD pathogenesis. Cell. Mol. Life Sci. 2020, 77, 2079-2090. [CrossRef]

6. Friedman, S.L.; Neuschwander-Tetri, B.A.; Rinella, M.; Sanyal, A.J. Mechanisms of NAFLD development and therapeutic strategies. Nat. Med. 2018, 24, 908-922. [CrossRef]

7. Schuster, S.; Cabrera, D.; Arrese, M.; Feldstein, A.E. Triggering and resolution of inflammation in NASH. Nat. Rev. Gastroenterol. Hepatol. 2018, 15, 349-364. [CrossRef]

8. Jensen, T.; Abdelmalek, M.F.; Sullivan, S.; Nadeau, K.J.; Cree-Green, M.; Roncal, C.; Nakagawa, T.; Kuwabara, M.; Sato, Y.; Kang, D.-H.; et al. Fructose and sugar: A major mediator of non-alcoholic fatty liver disease. J. Hepatol. 2018, 68, 1063-1075. [CrossRef] [PubMed]

9. Stefan, N.; Häring, H.-U.; Cusi, K. Non-alcoholic fatty liver disease: Causes, diagnosis, cardiometabolic consequences, and treatment strategies. Lancet Diabetes Endocrinol. 2019, 7, 313-324. [CrossRef]

10. Da Silva, B.P.; Anunciação, P.C.; Matyelka, J.C.D.S.; Lucia, C.M.D.; Martino, H.S.D.; Pinheiro-Sant'Ana, H.M. Chemical composition of Brazilian chia seeds grown in different places. Food Chem. 2017, 221, 1709-1716. [CrossRef]

11. Grancieri, M.; Martino, H.S.D.; De Mejia, E.G. Chia Seed (Salvia hispanica L.) as a Source of Proteins and Bioactive Peptides with Health Benefits: A Review. Compr. Rev. Food Sci. Food Saf. 2019, 18, 480-499. [CrossRef]

12. Grancieri, M.; Martino, H.S.D.; De Mejia, E.G. Protein Digests and Pure Peptides from Chia Seed Prevented Adipogenesis and Inflammation by Inhibiting PPAR $\gamma$ and NF-кB Pathways in 3T3L-1 Adipocytes. Nutrients 2021, 13, 176. [CrossRef] [PubMed] 
13. Mishima, M.D.V.; Ladeira, L.C.M.; da Silva, B.P.; Toledo, R.C.L.; de Oliveira, T.V.; Costa, N.M.B.; Martino, H.S.D. Cardioprotective action of chia (Salvia hispanica L.) in ovariectomized rats fed a high fat diet. Food Funct. 2021, 12, 3069-3082. [CrossRef] [PubMed]

14. Vuksan, V.; Jenkins, A.; Brissette, C.; Choleva, L.; Jovanovski, E.; Gibbs, A.; Bazinet, R.; Au-Yeung, F.; Zurbau, A.; Ho, H.; et al. Salba-chia (Salvia hispanica L.) in the treatment of overweight and obese patients with type 2 diabetes: A double-blind randomized controlled trial. Nutr. Metab. Cardiovasc. Dis. 2017, 27, 138-146. [CrossRef]

15. Enes, B.N.; Moreira, L.P.D.; Silva, B.P.; Grancieri, M.; Lúcio, H.G.; Venâncio, V.P.; Mertens-Talcott, S.U.; Rosa, C.O.B.; Martino, H.S.D. Chia seed (Salvia hispanica L.) effects and their molecular mechanisms on unbalanced diet experimental studies: A systematic review. J. Food Sci. 2020, 85, 226-239. [CrossRef]

16. Enes, B.N.; Moreira, L.D.P.D.; Toledo, R.C.L.; Moraes, É.A.; Moreira, M.E.D.C.; Hermsdorff, H.H.M.; Noratto, G.; Mertens-Talcott, S.U.; Talcott, S.; Martino, H.S.D. Effect of different fractions of chia (Salvia hispanica L.) on glucose metabolism, in vivo and in vitro. J. Funct. Foods 2020, 71, 104026. [CrossRef]

17. AOAC. Official Methods of Analysis of AOAC International: Agricultural Chemicals, Contaminants Drugs; AOAC International: Gaithersburg, MD, USA, 2012; Volume 16.

18. Bloor, S.J. Overview of methods for analysis and identification of flavonoids. Methods Enzymol. 2001, 335, 3-14. [CrossRef]

19. Singleton, V.L.; Orthofer, R.; Lamuela-Raventós, R.M. Analysis of total phenols and other oxidation substrates and antioxidants by means of folin-ciocalteu reagent. Methods Enzymol. 1999, 299, 152-178.

20. AOCS. Official Methods and Recommended Practices of the American Oil Chemists' Society; American Oil Chemists Society: Champaign, IL, USA, 1990.

21. Lutz, A. Óleos E Gorduras. In Métodos Físicos-Quimicos Para Análise Aliment; Instituto Adolfo Lutz: Sao Paulo, Brazil, 2008; p. 1020.

22. Murrieta, C.; Hess, B.; Rule, D. Comparison of acidic and alkaline catalysts for preparation of fatty acid methyl esters from ovine muscle with emphasis on conjugated linoleic acid. Meat Sci. 2003, 65, 523-529. [CrossRef]

23. Livak, K.J.; Schmittgen, T.D. Analysis of Relative Gene Expression Data Using Real-Time Quantitative PCR and the $2^{-\Delta \Delta C T}$ Method. Methods 2001, 25, 402-408. [CrossRef]

24. Bradford, M.M. A rapid and sensitive method for the quantitation of microgram quantities of protein utilizing the principle of protein-dye binding. Anal. Biochem. 1976, 72, 248-254. [CrossRef]

25. Marklund, S.L. Product of extracellular-superoxide dismutase catalysis. FEBS Lett. 1985, 184, 237-239. [CrossRef]

26. Green, L.C.; Wagner, D.A.; Glogowski, J.; Skipper, P.L.; Wishnok, J.S.; Tannenbaum, S.R. Analysis of Nitrate, Nitrite, and [15N] Nitrate in Biological Fluids. Anal. Biochem. 1982, 126, 131-138. [CrossRef]

27. Cupertino, M.C.; Costa, K.L.C.; Santos, D.C.M.; Novaes, R.D.; Condessa, S.S.; Neves, A.C.; Oliveira, J.; Matta, S.L.P. Long-lasting morphofunctional remodelling of liver parenchyma and stroma after a single exposure to low and moderate doses of cadmium in rats. Int. J. Exp. Pathol. 2013, 94, 343-351. [CrossRef] [PubMed]

28. Turlin, B.; Mendler, M.H.; Moirand, R.; Guyader, D.; Guillygomarc'H, A.; Deugnier, Y. Histologic Features of the Liver in Insulin Resistance-Associated Iron Overload. Am. J. Clin. Pathol. 2001, 116, 263-270. [CrossRef]

29. Kleiner, D.E.; Brunt, E.M.; Van Natta, M.; Behling, C.; Contos, M.J.; Cummings, O.W.; Ferrell, L.D.; Liu, Y.-C.; Torbenson, M.S.; Unalp-Arida, A.; et al. Design and validation of a histological scoring system for nonalcoholic fatty liver disease. Hepatology 2005, 41, 1313-1321. [CrossRef] [PubMed]

30. Bovi, A.P.D.; Marciano, F.; Mandato, C.; Siano, M.A.; Savoia, M.; Vajro, P. Oxidative Stress in Non-alcoholic Fatty Liver Disease. An Updated Mini Review. Front. Med. 2021, 8, 165. [CrossRef]

31. Marineli, R.D.S.; Moraes, É.A.; Lenquiste, S.A.; Godoy, A.T.; Eberlin, M.N., Jr. Chemical characterization and antioxidant potential of Chilean chia seeds and oil (Salvia hispanica L.). LWT-Food Sci. Technol. 2014, 59, 1304-1310. [CrossRef]

32. Oliveira-Alves, S.C.; Vendramini-Costa, D.B.; Cazarin, C.B.B.; Junior, M.R.M.; Ferreira, J.P.B.; da Silva, A.B.; Prado, M.A.; Bronze, M. Characterization of phenolic compounds in chia (Salvia hispanica L.) seeds, fiber flour and oil. Food Chem. 2017, 232, 295-305. [CrossRef]

33. da Silva, B.P.; Toledo, R.C.L.; Grancieri, M.; Moreira, M.E.D.C.; Medina, N.R.; Silva, R.R.; Costa, N.M.B.; Martino, H.S.D. Effects of chia (Salvia hispanica L.) on calcium bioavailability and inflammation in Wistar rats. Food Res. Int. 2019, 116, 592-599. [CrossRef]

34. Martinez, O.D.M.; Theodoro, J.M.V.; Grancieri, M.; Toledo, R.C.L.; Queiroz, V.A.V.; de Barros, F.A.R.; Martino, H.S.D. Dry heated whole sorghum flour (BRS 305) with high tannin and resistant starch improves glucose metabolism, modulates adiposity, and reduces liver steatosis and lipogenesis in Wistar rats fed with a high-fat high-fructose diet. J. Cereal Sci. 2021, 99, 103201. [CrossRef]

35. Creus, A.; Ferreira, M.R.; Oliva, M.E.; Lombardo, Y.B. Mechanisms Involved in the Improvement of Lipotoxicity and Impaired Lipid Metabolism by Dietary $\alpha$-Linolenic Acid Rich Salvia hispanica L (Salba) Seed in the Heart of Dyslipemic Insulin-Resistant Rats. J. Clin. Med. 2016, 5, 18. [CrossRef]

36. Fortino, M.; Oliva, M.E.; Rodriguez, S.; Lombardo, Y.; Chicco, A. Could post-weaning dietary chia seed mitigate the development of dyslipidemia, liver steatosis and altered glucose homeostasis in offspring exposed to a sucrose-rich diet from utero to adulthood? Prostaglandins Leukot. Essent. Fat. Acids 2017, 116, 19-26. [CrossRef] [PubMed]

37. Marineli, R.D.S.; Lenquiste, S.A.; Moraes, É.A.; Maróstica, M.R. Antioxidant potential of dietary chia seed and oil (Salvia hispanica L.) in diet-induced obese rats. Food Res. Int. 2015, 76, 666-674. [CrossRef] 
38. Han, K.; Li, X.Y.; Zhang, Y.Q.; He, Y.L.; Hu, R.; Lu, X.L.; Li, Q.J.; Hui, J. Chia Seed Oil Prevents High Fat Diet Induced Hyperlipidemia and Oxidative Stress in Mice. Eur. J. Lipid Sci. Technol. 2020, 122, 1-9. [CrossRef]

39. Xu, H.; Zhao, Q.; Song, N.; Yan, Z.; Lin, R.; Wu, S.; Jiang, L.; Hong, S.; Xie, J.; Zhou, H.; et al. AdipoR1/AdipoR2 dual agonist recovers nonalcoholic steatohepatitis and related fibrosis via endoplasmic reticulum-mitochondria axis. Nat. Commun. 2020, 11, 5807. [CrossRef]

40. Nelson, D.L.; Cox, M.M. Principios de Bioquimica de Lehninger, 6th ed.; Artmed Editora: Porto Alegre, Brazil, 2014.

41. De Souza, T.; da Silva, S.V.; Fonte-Faria, T.; Nascimento-Silva, V.; Barja-Fidalgo, C.; Citelli, M. Chia oil induces browning of white adipose tissue in high-fat diet-induced obese mice. Mol. Cell. Endocrinol. 2020, 507, 110772. [CrossRef] [PubMed]

42. Fonte-Faria, T.; Citelli, M.; Atella, G.C.; Raposo, H.F.; Zago, L.; de Souza, T.; da Silva, S.V.; Barja-Fidalgo, C. Chia oil supplementation changes body composition and activates insulin signaling cascade in skeletal muscle tissue of obese animals. Nutrition 2019, 58, 167-174. [CrossRef] [PubMed]

43. Calder, P.C. Omega-3 fatty acids and inflammatory processes: From molecules to man. Biochem. Soc. Trans. 2017, 45, 1105-1115. [CrossRef]

44. Pawlak, M.; Lefebvre, P.; Staels, B. Molecular mechanism of PPAR $\alpha$ action and its impact on lipid metabolism, inflammation and fibrosis in non-alcoholic fatty liver disease. J. Hepatol. 2015, 62, 720-733. [CrossRef]

45. Korbecki, J.; Bobiński, R.; Dutka, M. Self-regulation of the inflammatory response by peroxisome proliferator-activated receptors. Agents Actions 2019, 68, 443-458. [CrossRef] [PubMed]

46. Da Silva, B.P.; Toledo, R.C.L.; Mishima, M.D.V.; Moreira, M.E.D.C.; Vasconcelos, C.M.; Pereira, C.E.R.; Favarato, L.S.C.; Costa, N.M.B.; Martino, H.S.D. Effects of chia (Salvia hispanica L.) on oxidative stress and inflammation in ovariectomized adult female Wistar rats. Food Funct. 2019, 10, 4036-4045. [CrossRef] [PubMed] 